\title{
Nuclear Magnetic Resonance Microimaging of Strawberry Flower Buds and Fruit
}

\author{
John L. Maas ${ }^{1}$ and Michael J. Line ${ }^{2}$ \\ Beltsville Agricultural Research Center, Agricultural Research Service, U.S. \\ Department of Agriculture, Beltsville, MD 20705
}

Additional index words. Fragaria $\times$ ananassa, MR, MRI, magnetic resonance microscopy, mobile proton

\begin{abstract}
Nuclear magnetic resonance (NMR) can be used to examine tissue structure and developmental changes during growth and maturation of plant organs nondestructively. Spin-lattice, relaxation time (T1)-weighted, inversion recovery, spin-echo images of strawberry (Fragaria $\times$ ananass Duch.) flower buds were acquired at 3 and 1 day before anthesis and receptacles at 4,10,15, and 25 days after anthesis (DAA). The central pith and ovules of flower buds imaged intensely with inversion echo times between 0.1 and 0.5 seconds. Achenes and the vascular cylinder, composed of vascular bundles surrounding the pith, were prominent in receptacles at 4 and 10 DAA. Vascular bundles leading to achene positions, cortex and pith tissues, and the vascular cylinder were evident in receptacles at all developmental stages. A general trend to homogeneity of structure was observed in images of receptacles nearing full maturity (25 DAA). Inversion recovery, spin-echo NMR microimaging may be useful for studying internal physicochemical changes in flower buds and fruit of strawberry and of other fruit crops.
\end{abstract}

Nuclear magnetic resonance (NMR) imaging permits noninvasive study of proton density (water concentration) and proton relaxation characteristics of water in plant tissues (Gassner, 1989). Protons in water molecules in tissues under a strong magnetic field, given radio frequency excitation, emit relaxation signals of intensities that are related to the differences in proton density and the degree to which water is structurally bound. The spinlattice relaxation time (T1) is a measure of relaxation of nuclei after stimulation with a radio frequency and dissipation of the excess energy of excited nuclei to the surrounding nuclear lattice. Spatially different protons resonate at different frequencies, and when three orthogonal gradients are applied, the data acquired can be transformed to generate a proton density map (image). Relaxation time images can be made of the interior of plant structures by controlling the magnetically excited volume ("slice") position, thickness, and resolution (Kramer et al., 1990). Thus, images of the interior of plant organs can be obtained nondestructively.

Received for publication 6 Jan. 1995. Accepted for publication 10 May 1995. Mention of a trademark or propriety does not constitute a guarantee or warranty of the product by the U.S. Dept. of Agriculture and does not imply its approval to the exclusion of other products that also may be suitable. The cost of publishing this paper was defrayed in part by the payment of page charges. Under postal regulations, this paper therefore must be hereby marked advertisement solely to indicate this fact.

${ }^{1}$ Research Plant Pathologist, Fruit Laboratory.

${ }^{2}$ Electrical Engineer, Environmental Chemistry Laboratory.
NMR has been used to image bound and free water in apple (Malus domestica Borkh.) (Faust et al., 1991; Liu et al., 1993) and blueberry (Vaccinium corymbosum L.) buds (Rowland et al., 1992) to determine dormancy status, to locate the distribution of extracellular ice in blackberry (Rubus subgenus Eubatus) and raspberry (Rubus idaeus L.) floral buds (Shaffer et al., 1990), and to detect vascular discontinuities in failed bud unions of grafted apple trees (Warmund et al., 1993). Fruit quality was determined by Wang and Wang (1989), who examined development of core breakdown in 'Bartlett' pears (Pyrus communis L.). Wang et al. (1988) studied the distribution of watercore in 'Red Delicious' apple, Clark and Forbes (1994) followed the development of chilling injury in persimmon (Diospyros sp.), and Gamble (1994) evaluated freezing effects in blueberry fruit tissue with NMR imaging techniques.

Developmental studies using NMR imaging have described the maturation process of tomato (Lycopersicon esculentum Mill.) (Saltveit, 1991) and ripening avocado (Persea americana Mill.) fruit (Bennett et al., 1987). Williamson et al. (1992a) studied changes in developing red raspberry fruit and Williamson et al. (1993) described the histology of mature gooseberry (Ribes grossularis L.) fruit with NMR microimaging. NMR images in these studies correlated well with anatomical features of the fruit. Using T1-weighted, inversion recovery, spin-echo NMR, Williamson et al. (1994) selectively imaged the vascular architecture of red raspberry fruit. Although the interpretation of NMR images is not always straight forward (Williamson et al., 1993), NMR offers a useful tool to nondestructively examine plant development, physicochemical relationships, crop quality, and disease development.

Study of fruit diseases using NMR (Goodman et al., 1992a; Maas and Line, 1995; Williamson et al., 1992b) also requires characterization of healthy fruit with this technique. Because strawberry fruit may become diseased over a range of maturity stages, our objective was to examine healthy strawberry receptacles at various stages of development using NMR imaging to develop background data essential for interpreting NMR images of disease development in strawberry fruit.

\section{Materials and Methods}

Image data were collected on a spectrometer (model MSL-400 MHz 9.4 T; Bruker Instruments, Billerica, Mass.) with microimaging capabilities. A standard, inversion recovery, spin-echo, imaging sequence using single-point NMR with one inversion pulse and an inversion recovery waiting delay, as described by Morris (1986), was used. Four or five $\mathrm{T} 1$-weighted, inversion recovery $\left(\mathrm{T} 1_{\mathrm{ir}}\right)$ images were collected at inversion times of $0.1,0.5,1.0,1.5$, and $2.0 \mathrm{sec}$. The most effective $\mathrm{T} 1_{\text {ir }}$ time series was from 0.1 to $1.5 \mathrm{sec}$. The imaging sequence repetition time was 2.0 sec for flower buds 3 and 1 day before anthesis (DBA), $2.5 \mathrm{sec}$ for receptacles 15 and 25 days after anthesis (DAA), and $4.0 \mathrm{sec}$ for receptacles 4 and 10DAA. The echo time was 13.12 mins. The number of data acquisitions was two; the number of lines and points per line were 256 complex frequency encode $\times 256$ phase encode. The field of view was $12 \times 12$ $\mathrm{mm}$ for flower buds, and for receptacles, it was $15 \times 15 \mathrm{~mm}$ (5 DAA), $20 \times 20 \mathrm{~mm}$ (10 DAA), or $27 \times 27 \mathrm{~mm}$ (15 and 25 DAA). Pixel sizes were $27 \times 27 \mu \mathrm{m}$ for flower buds, receptacles 4 and $10 \mathrm{DAA}$, and $117 \times 117 \mu \mathrm{m}$ for receptacles 15 and 25 DAA. The magnetically excited volume (slice) thickness was $500 \mu \mathrm{m}$.

Freshly detached strawberry flower buds estimated to be 3 and 1 DBA, young receptacles with calyx $4 \mathrm{DAA}$, green receptacles 10 DAA, white receptacles 15 DAA, and nearly fully colored fruit (80\% red) 25 DAA of a field-grown advanced selection (MDUS 5054) of $F$. $\times$ ananassa were placed into glass NMR tubes (23 $\mathrm{mm}$ in diameter) for NMR microimaging

The smallest subjects (3 DBA buds) were $3 \mathrm{~mm}$ in diameter. The largest fruit examined were $23 \mathrm{~mm}$ in diameter. Fruit size was limited by the size of the magnetic coil that could be used with this NMR equipment; thus, primary, secondary, and tertiary receptacles were used. However, the size limitation gave the opportunity to achieve a great degree of magnification and clarity of images due to the relatively small pixel sizes. Samples were examined only in cross-sections, and interpretation of images are based on published anatomical descriptions (Aspuria and Fujime, 1995; Darrow, 1966; Galletta and Bringhurst, 1990; Havis, 1943; Szczesniak and Smith, 1969) and dissection of fresh flower buds (Fig.1) and fruit (Fig. 2).

HortScience, Vol. 30(5), August 1995 


\section{Results and Discussion}

T1-weighted inversion recovery images of flower buds 3 and 1 DBA. Structures evident in images of buds are the central pith and surrounding vascular cylinder (VC; Fig. 2), vascular bundles extending from the $\mathrm{VC}$ to ovules, anthers, petals, and two overlapping whorls of sepals that make up the calyx in the 3 DBA and 1 DBA flowers (Fig. 3 a and b). Flowers of $F$. $\times$ ananassa characteristically have one whorl of five petals, but cultivars may have either one or two whorls of sepals, depending on genotype (Darrow, 1966). In some cases, small, bright dots between the anther sacks and ovules can be seen that may either be stigmas or styles (Fig. 3b; $\mathrm{T} 1_{\text {ir }} 1.5 \mathrm{sec}$ at pointer). In most cases, anthers appear in an " $\mathrm{X}$ " configuration, but entire anther sacks are occasionally evident in a "figure-8" configuration in the 1 DBA flower bud (Fig. $3 \mathrm{~b}, \mathrm{~T} 1_{\text {ir }} 0.5$ at pointer and $1.0 \mathrm{sec}$ ). Pollen did not image at any $\mathrm{T} 1_{\mathrm{ir}}$ time.

T1-weighted inversion recovery images of young receptacles at 4 DAA with calyx. Images of green receptacles (6 $\mathrm{mm}$ in diameter) show the calyx as a faint outer ring, enclosing the receptacle (Fig. 3c). Immature achenes are readily evident, and in most cases, they appear uniformly solid in structure. However, the integument of some achenes was imaged, but the contents were not at $\mathrm{T} 1_{\mathrm{ir}}$ of 0.5 (at pointer) and $1.0 \mathrm{sec}$. Due to the small size of the receptacles in relation to the NMR slice size $(500 \mu \mathrm{m})$, entire vascular traces are evident, leading from the $\mathrm{VC}$ through the cortex to achene positions (Fig. 3c; 0.1 and $1.5 \mathrm{sec}$ at pointer). The $\mathrm{VC}$ is particularly apparent in images as a discontinuous series of vascular bundles arranged in a single rank surrounding the pith $\left(\mathrm{T} 1_{\text {ir }} 1.0 \mathrm{sec}\right.$ at pointer $)$. Williamson et al. (1994) discerned individual vascular bundles in the vascular system of red raspberry fruit and also distinguished xylem from phloem tissues using spin-echo imaging. We were unable to differentiate xylem and phloem tissues here, although these tissues are evident in discrete vascular bundles composing the VC in conventional histological preparations of strawberry fruit (Cheng and Breen, 1992).

T1-weighted inversion recovery images of green receptacle $10 D A A$. Images of the larger green receptacle $(15 \mathrm{~mm}$ in diameter) show achenes positioned slightly depressed into the cortex (Fig. 4a; $1_{\text {ir }} 1.5 \mathrm{sec}$ at pointer). Vascular traces to achenes appear less continuous from the $\mathrm{VC}$ to achenes due to the larger size of the receptacle in relation to the NMR slice (Fig. $4 \mathrm{a} ; \mathrm{T}_{\text {ir }} 1.0$ and $1.5 \mathrm{sec}$ ). The vascular traces become oriented away from the long axis of the receptacle and at an acute angle from the $\mathrm{VC}$ to achenes as the receptacle develops (Fig. 2). The VC also is apparent as a discontinuous series of vascular bundles surrounding the pith (Fig. $4 \mathrm{a} ; \mathrm{T}_{\mathrm{ir}} 0.1$ and 1.0 $\mathrm{sec})$.

T1-weighted inversion recovery images of white $(15 D A A)$ and $80 \%$ ripe $(25 D A A)$ receptacles. Much of the detail apparent in images of younger receptacles (Figs. 3c and 4a) is not apparent in white (Fig. 4b) or red (Fig. 4c) fruit. Part of this is due to less magnification in these images $(117 \times 117 \mu \mathrm{m}$ pixel size $) \mathrm{com}$ pared to that available for the smaller, younger receptacles and buds $(27 \times 27 \mu \mathrm{m}$ pixel size $)$. The achenes of these fruit were positioned in the slight concavities on the outer receptacle perimeter. However, in no cases were achenes imaged in receptacles 15 or 25 DAA, although the concavities are evident in images (Fig. 4 a and b). Similarly, Williamson et al. (1992a) were unable to image internal structures of mature seeds of red raspberry fruit. However, Goodman et al. (1992b) showed the presence of mobile protons and some poorly defined internal structure of single, isolated, red raspberry seeds using spin-echo NMR projection imaging. Vascular traces to achene positions are evident as is the VC. In some images, the VC still can be seen as a discontinuous series of vascular bundles (Fig. $4 \mathrm{a}-\mathrm{c}$ at $\mathrm{T} 1_{\text {ir }} 0.5$ and $1.0 \mathrm{sec})$.

Relative T1-weighted water proton relaxation characteristics of tissues. Comparison of $\mathrm{T} 1_{\mathrm{ir}}$ images of flower buds (Fig. $3 \mathrm{a}$ and $\mathrm{b}$ ) with postanthesis receptacles (Figs. 3c and $4 \mathrm{a}-\mathrm{c})$ show that the proton relaxation characteristics of water protons, cell structure, or in the pith and vascular tissues apparently change markedly with development of the receptacles. For example, the pith tissue appears bright in buds at $\mathrm{T} 1_{\text {ir }} 0.1 \mathrm{sec}$, but at $\mathrm{T} 1_{\text {ir }} 0.5 \mathrm{sec}$, it is dark (Fig. $3 \mathrm{a}$ and b). At $\mathrm{T}_{1 \mathrm{r}} 1.0$ and $1.5 \mathrm{sec}$, pith of flower buds also is bright but not as intensely so as at $\mathrm{T} 1_{\text {ir }} 0.1 \mathrm{sec}$. In images of the $4 \mathrm{DAA}$ green receptacle (Fig. $3 \mathrm{c}$ ), the $\mathrm{T} 1_{\text {ir }} 0.1-$ and 0.5 -sec pith images are bright; the $\mathrm{T} 1_{\text {ir }} 1.0$ - and 1.5 -sec pith images are dark. A similar sequence is apparent in pith images of $10 \mathrm{DAA}$ fruit (Fig. 4a); however, the central portion of the pith is somewhat darker than near the VC. This sequence becomes less apparent with the more mature receptacles of 15 DAA (Fig. 4b) and 25 DAA (Fig. 4c). For 4-, 10-, 15-, and 25DAA fruit in the $\mathrm{T} 1_{\mathrm{ir}} 1.0$ - and 1.5 -sec series (Figs. $3 \mathrm{c}$ and $4 \mathrm{a}-\mathrm{c}$ ), a broad ring around the pith is evident. Pith cells nearest the VC are smaller and have fewer air spaces between cells than those in the central pith (Cheng and

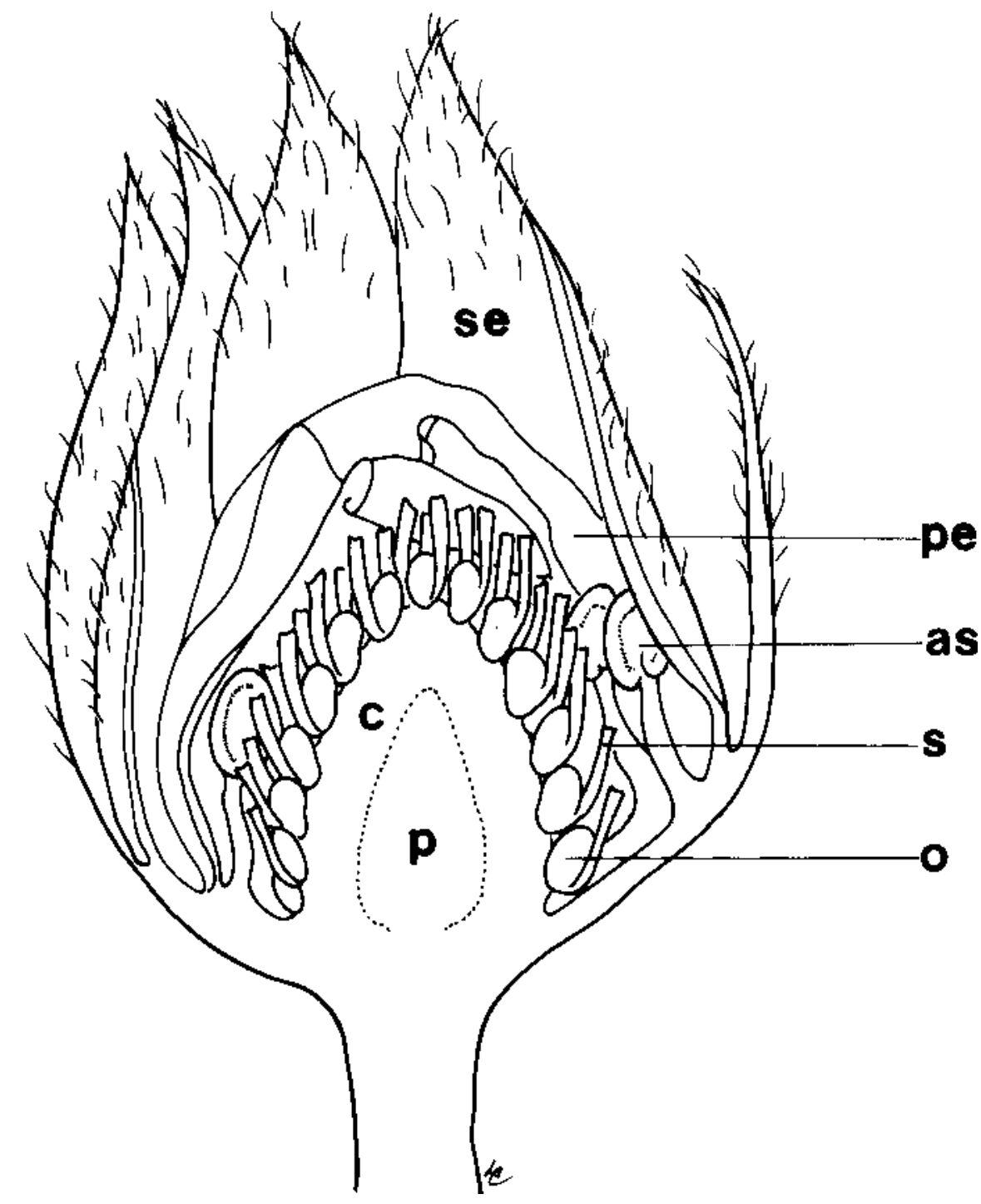

Fig. 1. Schematic of a strawberry flower bud in longitudinal cross section showing the central (p) pith, (c) cortex, (o) ovules, and (s) styles of pistils; bilobed (as) anther sacs of stamens; and overlapping (pe) petals and (se) sepals. (Drawing by Lynda Chandler.) 
Breen, 1992; Szczesniak and Smith, 1969) and likely are physiologically more active than central pith cells. There apparently is more free water in these cells, which could explain the relative brightness of these cells evident in the $\mathrm{T} 1_{\text {ir }} 1.0$ - and 1.5 -sec images. The increase in cell size toward the center of the pith is accentuated in large primary and secondary fruit of many cultivars, where the cells of the central pith become large and disorganized and may dissociate to form a void (Fig. 1) (Darrow, 1966; Szczesniak and Smith, 1969).

Although cortex cells of strawberry fruit continue to be meristematic until 10 DAA (Cheng and Breen, 1992) and possibly to 15 DAA with cells nearest the epidermis (Darrow, 1966), no readily apparent distinction in cell function was detected in images. Exceptions may be that the cortex appears slightly darker near the epidermis than closer to the $\mathrm{VC}$ in images of the 10-DAA receptacle (Fig. 4a) at $\mathrm{T} 1_{\mathrm{ir}} 0.1$ and $0.5 \mathrm{sec}$; also, a narrow bright ring at the outer cortex periphery in images at $\mathrm{T} 1_{\mathrm{ir}}$ 1.0 and $1.5 \mathrm{sec}$ may represent the epidermal cell layers. Examination of strawberry fruit by scanning electron microscopy showed that the normal epidermis between achenes of strawberry fruit consists of a layer of flattened and closely packed parenchyma cells that generally are either undifferentiated or, in some genotypes, differentiated into guard cells of stomata or base cells of trichomes and covered by a thin, amorphous, cuticular layer but with no external layer of wax platelets (Maas, unpublished data).

Imaging of plant cortex tissue may be modified by the physical presence of cell wall and air space interfaces that constitute, in NMR terminology, susceptibility boundaries (Callaghan, 1991). Thus, the density and size of air spaces influence the appearance of images of cortex tissue. A tissue composed of tightly packed cells with few or no air spaces may image brighter compared to an adjacent tissue with more susceptibility boundaries. As air spaces become increasingly large, the NMR signal is lost through diffusion-dependent dephasing of the magnetism before signal acquisition; thus, the tissue appears darker than tissues with small, closely packed cells with no air spaces (Bowtell et al., 1990). Air spaces are present in the cortex and pith of strawberry fruit and enlarge as the fruit matures (Havis, 1943; Szczesniak and Smith, 1969). The apparent homogeneity of the nonvascular cortex in images of 10-, 15-, and 25-DAA receptacles suggests that the air spaces are fairly uniform in size and are uniformly distributed throughout the cortex of each fruit as the fruit matures.

Except for vascular traces, the cortex of green, white, and red fruit appear homogeneous as a tissue, although cell sizes are not uniform (Cheng and Breen, 1992). Lack of structure detail in the cortex of images in Fig. $4 \mathrm{~b}$ and $\mathrm{c}$ is due to interference frequencies in the magnetic field, although vascular structure still is apparent. This loss of structure detail in cortex images is not comparable to images of bruise damage where cell compartmentation is destroyed and structure distinctions are lost when air spaces are filled with cellular fluids,

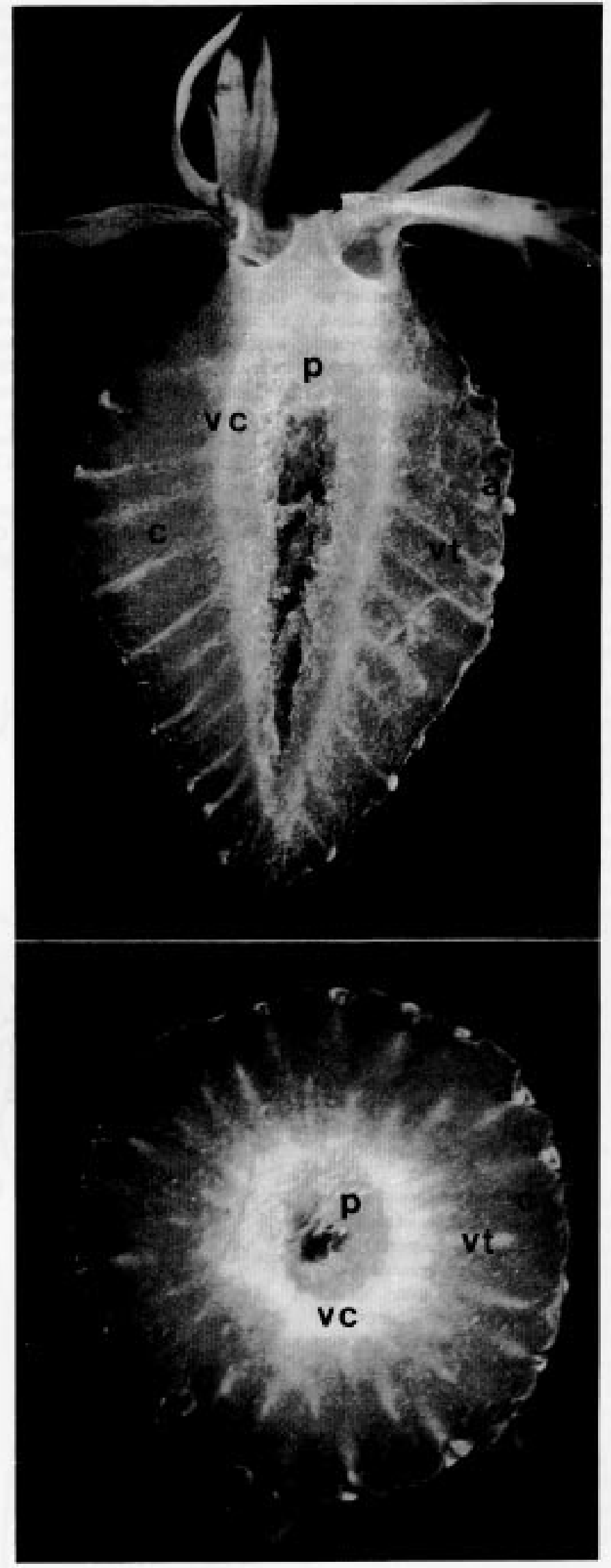

Fig. 2. Mature strawberry receptacle in medial (top) longitudinal and (bottom) cross section. Note the separation of cells in the central (p) pith, which forms a central cavity; central (ve) vascular cylinder around the pith, and (vt) vascular traces leading obliquely from the vascular cylinder to (a) achenes. Achenes are situated in slight depressions of the outer (c) cortex of this fruit. 


\section{Flower bud (Days before anthesis)}

\section{1}

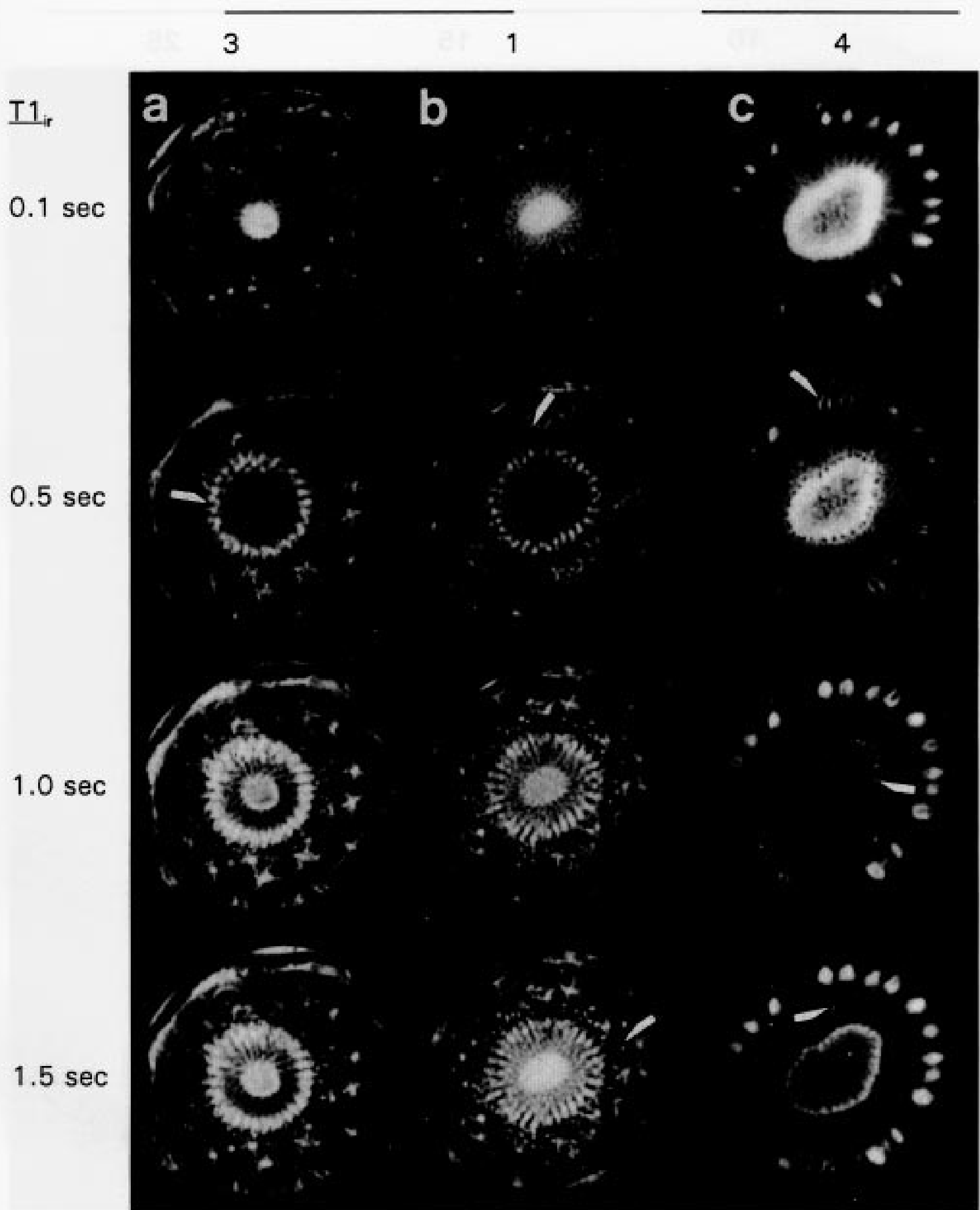

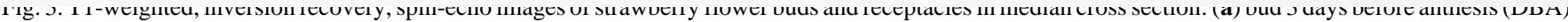
and $3 \mathrm{~mm}$ in diameter, (b) bud $1 \mathrm{DBA}$ and $4 \mathrm{~mm}$ in diameter, and (c) receptacle at 4 days after anthesis (DAA) and $10 \mathrm{~mm}$ in diameter. Inversion recovery times, from top to bottom: 0.1, 0.5, 1.0, and $1.5 \mathrm{sec}$. Repetition time was $2.0 \mathrm{sec}$ for buds and $4.0 \mathrm{sec}$ for receptacle 4 DAA. Echo time was $13.12 \mathrm{~min}$. The number of data acquisitions was two for each subject, and the number of lines and points per line was $256 \times 256$. The field of view was $12 \times 12$ mm for buds and 15 $\times 15$ for receptacles 4 DAA. Pixel size was $27 \times 27 \mu \mathrm{m}$ and slice thickness was $500 \mu \mathrm{m}$. Consult Figs. 1 and 2 and text for structural features. 


\section{Receptacle (Days after anthesis)}

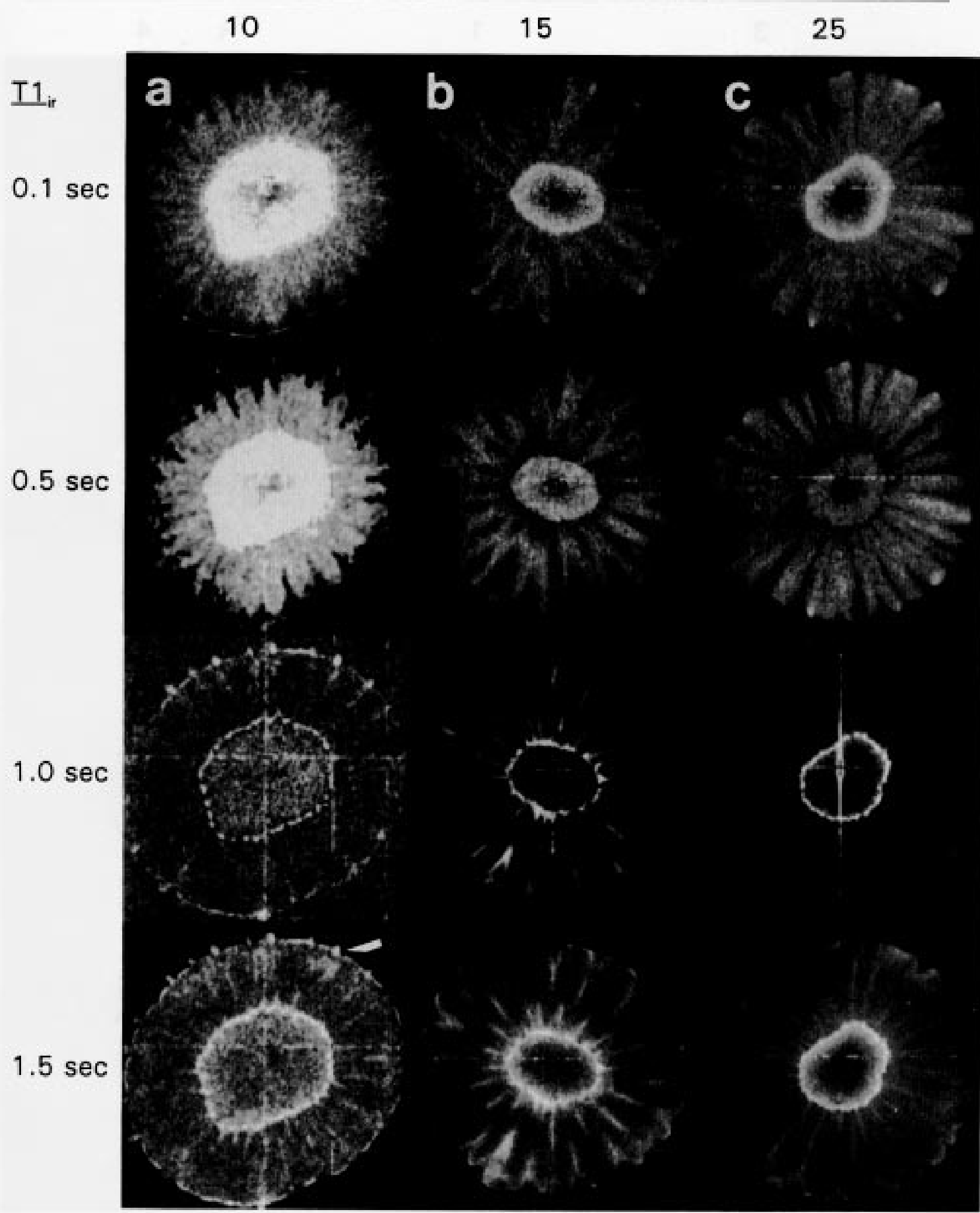

Fig. 4. T1-weighted, inversion recovery, spin-echo images of strawberry receptacles ( $22 \mathrm{~mm}$ in diameter) in median cross section: (a) receptacle 10 days after anthesis (DAA), (b) receptacle 15 DAA, and (c) receptacle 25 DAA. Inversion recovery times, from top to bottom: 0.1, 0.5, 1.0, and 1.5 sec. Repetition time was $4.0 \mathrm{sec}$ for receptacle $10 \mathrm{DAA}$ and $2.5 \mathrm{sec}$ for receptacles 15 and $25 \mathrm{DAA}$. Echo time was $13.12 \mathrm{~min}$, and the number of data acquisitions was two for each subject. The number of lines and points per line was $256 \times 256$. The field of view was $20 \times 20$ for receptacle 10 DAA and $27 \times 27$ for receptacles 15 and 25 DAA. Pixel size was $117 \times 117 \mu \mathrm{m}$ and slice thickness was $500 \mu \mathrm{m}$. Consult Figs. 1 and 2 and text for structural features. 
resulting in a uniformly bright area in the image (Maas et al., 1993a, 1993b).

Although the pith and cortex are comprised of parenchyma cells, their physiological functions may be quite different in that the cortex may be the initial sink for photosynthetic assimilates translocated to the fruit.

The VC and vascular traces to achenes, only slightly apparent in the $\mathrm{T} 1_{\mathrm{ir}} 1.0$ - and 1.5 sec images of 3-DBA buds (Fig. 3a), imaged somewhat differently. The VC in $\mathrm{T}_{\text {ir }} 1.0-\mathrm{sec}$ images of small and large green receptacles (4 and 10 DAA, respectively) appear as a discontinuous system of vascular bundles (Figs. 3c and 4a). Individual vascular bundles are apparent, although less distinctly, in $\mathrm{T} 1_{\text {ir }} 1.5-\mathrm{sec}$ images. No distinction of individual vascular bundles is apparent in $\mathrm{T} 1_{\text {ir }} 1.0$ - or 1.5 -sec images in white or red (15 and 25 DAA) fruit (Fig. 4 b and c). Apparent voids (dark spots) can be seen in $\mathrm{T} 1_{\text {ir }} 0.5$ - (Fig. 3c) and $0.1-\mathrm{sec}$ (Fig. 4a) images of the VC. These images possibly are at the $\mathrm{T} 1_{\mathrm{ir}}$ time, where $\mathrm{y}=0$ in the relaxation curve for the individual vascular bundles [e.g., as also seen in $\mathrm{T}_{1 \mathrm{ir}} 0.5$-sec images in white and red fruit (15 and 25 DAA) (Fig. $4 \mathrm{~b}$ and c)]. The apparently bright, but less distinct, images of the VC of fruit 4,10 , 15 , and 25 DAA shown in $\mathrm{T} 1_{\mathrm{ir}} 0.5$-sec images (Figs. $3 \mathrm{c}$ and $4 \mathrm{a}-\mathrm{c}$ ) suggest the possibility that cell types other than vessels and fibers also were imaged. Examination of vascular traces leading to achene positions reveals that the vascular trace images were bright with $\mathrm{T} 1_{\mathrm{ir}} 1.0$ and $1.5 \mathrm{sec}$ but were dark in relation to the bright cortex background with $\mathrm{T} 1_{\mathrm{ir}} 0.1$ and 0.5 sec.

Vascular traces appear discontinuous in 15- and 25-DAA receptacles (Fig. 4 b and c); however, this result is due to the angle of their development in the receptacle in relation to the plane of the NMR slice. As strawberry receptacles grow, they often become longer than wider, with the cortex expanding more than the pith, resulting in traces that develop in a spiral at an obtuse angle away from the base of the receptacle (Darrow, 1966; Havis, 1943; Takeda et al., 1990).

Unfertilized ovules and immature achenes imaged intensely bright in receptacles from 3 DBA to 4 DAA (Fig. 3 b and c) and imaged to some degree in 10-DAA (Fig. 4a) receptacles. Images of some achenes (e.g., Fig. $3 \mathrm{c} ; \mathrm{T} 1_{\mathrm{ir}} 0.5$ $\mathrm{sec}$ ) appear as bright rings surrounding a dark center. Because like images do not appear in the other $\mathrm{T} 1_{\mathrm{ir}}$ images, it can be assumed that the achenes were differentially imaged as the probable maternal integument or pericarp (represented by the bright ring) and embryo (central dark area in this image but bright in the other $\mathrm{T} 1_{\mathrm{ir}}$ images); thus, achenes show different $\mathrm{T} 1$ values for their water content. Black images could be interpreted as the tissue having water protons bound so tightly with other cellular components that their $\mathrm{T} 1$ values are below the lowest $\mathrm{T} 1_{\text {ir }}$ time $(0.1 \mathrm{sec})$ used.

Because the strawberry achene botanically is a fruit and not a seed, a direct comparison with true seeds may not be entirely appropriate. The pericarp of strawberry achenes often is green on immature receptacles, sometimes with numerous stomata in the epidermis (Maas, unpublished data), suggesting that the immature achene has photosynthetic capabilities and may supply some photosynthetic assimilates to the developing embryo. Achenes were not imaged after 10 DAA (Fig. 4a), which roughly corresponds to the time of achene development when the nuclear endosperm starts to change to the cellular state following rapid growth of the embryo (Thompson, 1963) and chlorophyll loss in the pericarp.

NMR images of soybean [Glycine max (L.) Merr.] seed show differential maturation and changes in water proton density and $\mathrm{T} 1$ values in seedcoat and embryo (Kano et al., 1990) that are strikingly similar to our images of strawberry achenes. According to Kano et al. (1990), as soybean seeds developed from anthesis, integument and embryo gained water and fresh weight as they enlarged, which were indicated as bright areas in T1 images. However, as the seed matured, the free-water content decreased in both; thus, corresponding $\mathrm{T} 1$ images were less bright. At maturity, soybean embryos did not image because of dehydration and presumably tight binding of the remaining cellular water with carbohydrates, proteins, and fatty acids. The seedcoat, however, continued to give bright images until it matured (Kano et al., 1990).

We have demonstrated that T1 NMR microimaging can be a useful tool for examining strawberry receptacles to noninvasively and nondestructively provide information on the development of receptacles. The occurrence of various developmental processes was evident, but resolution of interpretation depends on a more complete knowledge of the physiology of the total process, rather than at discrete "phases" of the process. Imaging effects can be used to help interpret these processes; nevertheless, interpretation of images must be done with caution and should be coupled with physiological studies to fully explore the usefulness of NMR microimaging. A series of T1-weighted inversion recovery images greatly aids interpretation of NMR image data in terms of physical plant tissue structure and physiological processes of the tissues that contribute to NMR microimages. Deriving images of plant tissues while physiological events are occurring is especially compelling because these processes may continue uninterrupted in a more or less normal state as the imaging process continues.

\section{Literature Cited}

Aspuria, J.R. and Y. Fujime. 1995. Eco-physiological studies in the analysis of dormancy in strawberry. Acta Hort. 395:97-104.

Bennett, A.B., G.M. Smith, and B.G. Nichols. 1987. Regulation of climacteric respiration in ripening avocado fruit. Plant Physiol. 83:973-976.

Bowtell, R.W., G.D. Brown, P.M. Glover, M. McJury, and P. Mansfield. 1990. Resolution of cellular structures by NMR microscopy at 11.7 . Philosophical Trans. Royal Soc. of London, Sect. A 33:457-464.

Callaghan, P.T. 1991. Principles of nuclear magnetic resonance microscopy. Clarendon Press, Oxford.
Cheng, G.W. and P.J. Breen. 1992. Cell count and size in relation to fruit size among strawberry cultivars. J. Amer. Soc. Hort. Sci.117:946-950.

Clark, C.J. and S.K. Forbes. 1994. Nuclear magnetic resonance imaging of the development of chilling injury in 'Fuyu' persimmon (Diospyros kaki). N.Z. J. Crop Hort. Sci. 22:209-215.

Darrow, G.M. 1966. The strawberry: History, breeding and physiology. Holt, Rinehart, and Winston, New York.

Faust, M., D. Liu, M.M. Millard, and G.W. Stutte. 1991. Bound versus free water in dormant apple buds-A theory for endodormancy. HortScience 26:887-890.

Galletta, G.J. and R.S. Bringhurst. 1990. Strawberry management, p. 83-156. In: G.J. Galletta and D.G. Himelrick (eds.). Small fruit crop management. Prentice Hall, Englewood Clifts, N.J.

Gamble, G.R. 1994. Non-invasive determination of freezing effects in blueberry fruit tissue by magnetic resonance imaging. J.Food Sci. 59(3):571573,610 .

Gassner, G. 1989. Magnetic resonance imaging in agricultural research, p. 405-428. In:P.E.Pfeffer and W.V. Gerasimowicz (eds.). Nuclear magnetic resonance in agriculture. CRC Press, Boca Raton, Fla.

Goodman, B.A., B. Williamson, and J.A. Chudek. 1992a. Non-invasive observation of the development of fungal infection in fruit. Protoplasma 166:107-109.

Goodman, B.A., B. Williamson, and J.A. Chudek. 1992b. Nucler magnetic resonance (NMR) microimaging of raspberry fruit: Further studies on the origin of the image. New Phytol. 122:529 535.

Havis, A.L. 1943. A developmental analysis of the strawberry fruit. J. Bot. 30:311-314.

Kano, H., N. Ishida, T. Kobayashi, and M. Koizumi. 1990. 'H-NMR imaging analysis of changes of free water distribution in barley and soybean seeds during maturation. Jpn. J. Crop Sci. 59(3):503-509.

Kramer, P.J., J.N. Siedow, and J.S. MacFall. 1990 Nuclear magnetic research on plants, p. 403 431. In: Y. Hashimoto, P.J. Kramer, H. Nonami, and B.R. Strain (eds.). Measurement techniques in plant science. Academic, New York.

Liu, D., M. Faust, M.M. Millard, M.J. Line, and G.W. Stutte. 1993. States of water in summerdormant apple buds determined by proton magnetic resonance imaging. J. Amer. Soc. Hort. Sci. 118:632-637.

Maas, J.L. and M.J. Line. 1995. Nuclear magnetic resonance (NMR) inversion recovery spin echo microimaging of fungus infections in strawberry fruit. Acta Hort. 398:241-247.

Maas, J.L., M.J. Line, M.M. Millard, and G.J. Galletta. 1993a. Nuclear magnetic resonance (NMR) micro-imaging: A different view of strawberry fruit. Adv. Strawberry Res. 11:6466.

Maas, J.L., M.M. Millard, M.J. Line, and G.J. Galletta. 1993b. Nuclear magnetic resonance microimaging of strawberry fruit. Acta Hort. 348:375-377.

Morris, P.G. 1986. Nuclear magnetic resonance imaging in medicine and biology. Clarendon, Oxford.

Rowland, L.J., D. Liu, M.M. Millard, and M.J. Line. 1992. Magnetic resonance imaging of water in flower buds of blueberry. HortScience 27:339 341.

Saltveit, M.E., Jr. 1991. Determining tomato fruit maturity with nondestructive in vivo nuclear magnetic resonance imaging. Postharvest Biol. Technol. 1:47-53.

Shaffer, K., M. Warmund, and M. George. 1990. Distribution of extracellular ice in blackberry 
and raspberry floral buds. Plant Physiol. Suppl. 93:87. (Abstr.)

Szczesniak, A.S. and B.J. Smith. 1969. Observations on strawberry texture: A three-pronged approach. J. Texture Studies 1:65-89.

Takeda, F., G.W. Lightner, and B.L. Upchurch. 1990. A rapid method of determining carpel numbers in strawberry flowers. HortScience 25:230.

Thompson, P.A. 1963. The development of embryo, endosperm, and nucellus tissues in relation to receptacle growth in the strawberry. Ann. Bot. 27:589-605.

Wang, C.Y. and P.C. Wang. 1989. Nondestructive detection of core breakdown in 'Bartlett' pears with nuclear magnetic resonance imaging.
HortScience 24:106-109.

Wang, C.Y., P.C. Wang, and M. Faust. 1988. Nondestructive detection of watercore in apple with nuclear magnetic resonance imaging. Scientia Hort. 35:227-234.

Warmund, M.R., B.H. Barritt, J.M. Brown, K.L. Schaffer, and B.R. Jeong. 1993. Detection of vascular discontinuity in bud unions of 'Jonagold' apple on Mark rootstock with magnetic resonance imaging. J. Amer. Soc. Hort. Sci. 118:92-96.

Williamson, B., B.A. Goodman, and J.A. Chudek. 1992a. Nuclear magnetic resonance (NMR) micro-imaging of ripening red raspberry fruits. New Phytol. 120:21-28.

Williamson, B., B.A. Goodman, and J.A. Chudek.
1993. The structure of mature gooseberry (Ribes grossularia) fruits revealed non-invasively by NMR microscopy. Micron 24(4):377-383.

Williamson, B., B.A. Goodman, J.A. Chudek, G. Hunter, and J.A.B. Lohman. 1994. The vascular architecture of the fruit receptacle of red raspberry determined by 3D NMR microscopy and surface-rendering techniques. New Phytol. 128:39-44.

Williamson, B., B.A. Goodman, J.A. Chudek, and D.J. Johnston. 1992b. Nuclear magnetic resonance (NMR) microimaging of soft fruits infected by Botrytis cinerea, p. 140-144. In: K. Verhoeff, N.E. Malathrakis, and B. Williamson (eds.). Advances in Botrytis research, Proc. 10th Botrytis Symp., Crete. 